\title{
Strategic Brand Management in the Market
}

\author{
ANATOLII MAZARAKI ${ }^{1}$, MYKHAILO TARASIUK ${ }^{2}$, YULIIA SOLONENKO ${ }^{3}$, OKSANA GALENKO ${ }^{4}$, \\ MARYNA LYSYNIUK ${ }^{5}$, DIANA FAYVISHENKO ${ }^{6}$ \\ ${ }^{1} \mathrm{KYIV}$ NATIONAL UNIVERSITY OF TRADE AND ECONOMICS, UKRAINE. \\ ${ }^{2}$ Department of Management and Marketing, KYIV NATIONAL LINGUISTIK UNIVERSITY, UKRAINE. \\ ${ }^{3}$ Department of Entrepreneurship, Corporate and Spatial Economics, VASYL' STUS DONETSK NATIONAL \\ UNIVERSITY, UKRAINE. \\ ${ }^{4}$ Department of International Accounting and Audit, KYIV NATIONAL ECONOMIC UNIVERSITY, UKRAINE. \\ ${ }^{5}$ Department of Public Relations and Journalism, KYIV NATIONAL UNIVERSITY OF CULTURE AND ARTS, UKRAINE. \\ ${ }^{6}$ Department of Journalism and Advertising, KYIV NATIONAL UNIVERSITY OF TRADE AND ECONOMICS, \\ UKRAINE. E-mail: fayvishenko.d@meta.ua
}

\begin{abstract}
The modern market is characterized by ups and downs associated with both external negative influences and expectations, and with the structural restructuring of the market. The result of these transformations was the transformation of the methodological and practical foundations of the formation, functioning and development of marketing and advertising activities, the leading role among which is the development and management of the company's brand.

The development and management of a brand, or the branding process in an enterprise should be strategic and holistic. The authors studied the theoretical basis for the development and promotion of a brand to the market and proposed directions for its improvement: an algorithm for creating a brand strategy and a comprehensive scheme for forming a strategy for the development and management of an enterprise brand. To assess the effectiveness of the brand management strategy, the authors proposed a system of indicators characterizing the process of brand development and management based on the BEES model, as well as a brand health diagram. The adequacy of the implementation of the proposed scheme for the formation of a strategy for the development and management of a brand of an enterprise is based on the fulfilment of specific requirements for an enterprise developing a brand, in particular, for the efficiency of the branding unit in its structure, forms and methods for assessing the rationality of management decisions, as well as for organizational and economic model of the enterprise in the market.
\end{abstract}

Keywords: strategic management, brand management, market, brand.

JEL Classification: M30, M31, L21

Received: 25 March 2021

Accepted: 4 April 2021 


\section{Introduction.}

In the era of globalization and intensification of competition in domestic and foreign markets, domestic companies need useful competitive advantages to ensure strong competitive positions, which, in particular, can be achieved through branding technologies (Dźwigoł et al, 2019). The brand is one of the most vital tools of modern marketing communications. The relevance and increasing attention to the problems of strategy formation and planning of measures to support and develop the brand are explained by the fact that brand awareness is an essential condition for stable operation of the enterprise in the market and a factor of its competitiveness.

\section{Literature review.}

Many foreign and domestic scientists, scientists, economists who have studied aspects of brand promotion, the importance of brand management have made a significant scientific contribution to the study of theoretical and practical problems of brand formation and development (Buil et al., 2016; Stošić-Mihajlović \& Trajković, 2020), context-oriented approaches to brand value (Johansen, 2018), improving the understanding of brand management (Heding et al., 2020), and other issues related to the effective management of various aspects of the enterprise (Mazaraki et al., 2020).

There are many definitions of "brand": The Dictionary of Business and Management defines a brand as "a name, mark, or symbol used to identify a seller's product and to distinguish it from a competitor's product." Walter Landor defined the brand as "a brand is a promise. By identifying and authenticating a product or service, it delivers a pledge of satisfaction and quality" (Vienne, 1999). In his book Building Strong Brands, David Aaker defines a brand as "a set of qualities associated with a brand name and a symbol that enhances (or weakens) the value of the product or service offered under that symbol" (Aaker, 1996).

Thus, the brand is an important marketing tool that determines the attitude of consumers to the brand, and hence sales, and profit levels, and other financial indicators. A brand is essentially a mark that denotes ownership - in legal terms as well (Kapferer, 2012).

It is also worth mentioning the distinctive features of the "trademark" and "brand". The word "brand" has entered the language of life relatively recently. The English verb "to brand" has the following meanings: "brand", "burn with red-hot iron", "leave an imprint", including - in memory. As a noun, it is a "brand", a "brand"; at a later time - "brand". In the general case, we can say that "brand" and "trademark" are synonymous words. At the same time, the coexistence of these two terms in Ukraine is connected with specific nuances inherent in them. The concept of "brand" in experts is associated primarily with the affiliation of the brand to the manufacturer or to the person who acquired the right to this brand. If we talk about the brand, then this term is embedded in a broader concept associated with the next stage of development of the brand, when it acquires additional value in the eyes of the consumer. A brand is mainly a name. It is not for nothing that Chinese sages say, "The unnamed does not exist". Therefore, the product name is considered as the first message to the consumer.

\section{The scientific basis for strategic brand management in the market.}

\subsection{Brand and branding.}

At the first stage, when the product enters the market, the brand must be associated with functional features that distinguish it from similar products. Only then, as the popularity of products, the brand will move into the social plane and begin to unite around a group of consumers.

Regarding branding as a type of consulting activity, we can say that it is designed to solve several problems. In the case when a trading company launches a new product, a special strategy is developed for it, to which the brand is attached. Where a company for one reason or another changes its market policy or restructures the product range, it is necessary to rebrand, i.e. to make 
specific changes that may affect not only the product name but also the entire corporate identity of the company. The purpose of rebranding is to change the consumer's perception of products or the image of the enterprise (Makasi et al., 2014).

The process of creating a brand consists of several stages. It all starts with conducting research in direct contact with the consumer. Then several variants of the name are made, which are checked for patent purity and offered for consideration by the customer. Besides, work on the brand includes the development of graphic elements of corporate identity and their media. But the most important thing is building a brand, strengthening it, positioning it in different dimensions. To succeed, a brand must live. To do this, the company must have an appropriate corporate culture.

When creating a brand, you need to focus on the main goal: to separate their products from others that have already flooded the market. The main components of a trademark are corporate style and further positioning of the trademark. Corporate identity is a way to distinguish the organization among others and fix its image in the minds of people (Buil et al., 2016). This is a specially designed scheme that covers everything related to creating a visible image. In Fig. 1 consider what applies to corporate identity.

1. Name. A right name can significantly contribute to the success of a product. Ideally, the brand name should have the following qualities: It should carry some hint of the benefits and rates of the product. For example, Grotto (decorative wall covering with a rock effect), Oasis (fruit drink), Kleenex (cleaning cloth), Frisp (light snack). It should be easy to pronounce, well-known and memorable (it is best to choose short names). Examples: Dufa (paint), Dove (soap), Hula Hoops (crispy potato slices in the form of a wedding ring). It must be individual. For example, Monto, Canon, Kodak, Candis. It should be easy (while preserving the content) translated into foreign languages; it can be registered and provide legal protection. A trademark cannot be registered if it affects the rights of existing names. Moreover, brands of a purely descriptive nature may not be subject to legal protection at all. Once chosen, the trademark name must be registered in the relevant Trademark Register - this will give trademark owners the right to intellectual property and prevent competitors from using the same name.

2. Logo. The company logo/sign is a symbol, drawing or special distinctive sign, sometimes a particular colour or designation. Ideally, the logo should solve six functions: 1. Actual, 2. Expressive, 3. Reference, 4. Impressive, 5. Poetic, 6. Metalinguistic.

The logo must be:

- easily recognizable;

- good to remember;

- be expressive, both large (on posters, placards, etc.) and small (on stickers, small labels, etc.);

- hint at the nature of the product;

- economical to use (meaning its reproduction on paper, some promotional activities, etc.).

Figure 1. The main components of the brand

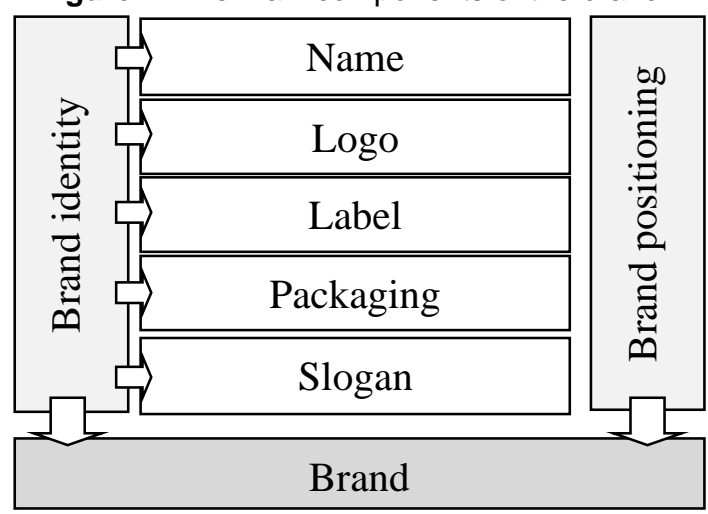

The TOP 10 most influential logos are as follows (Fig. 2). 
Figure 2. The most influential logos (compiled by the authors based on (The 10 most iconic logos))

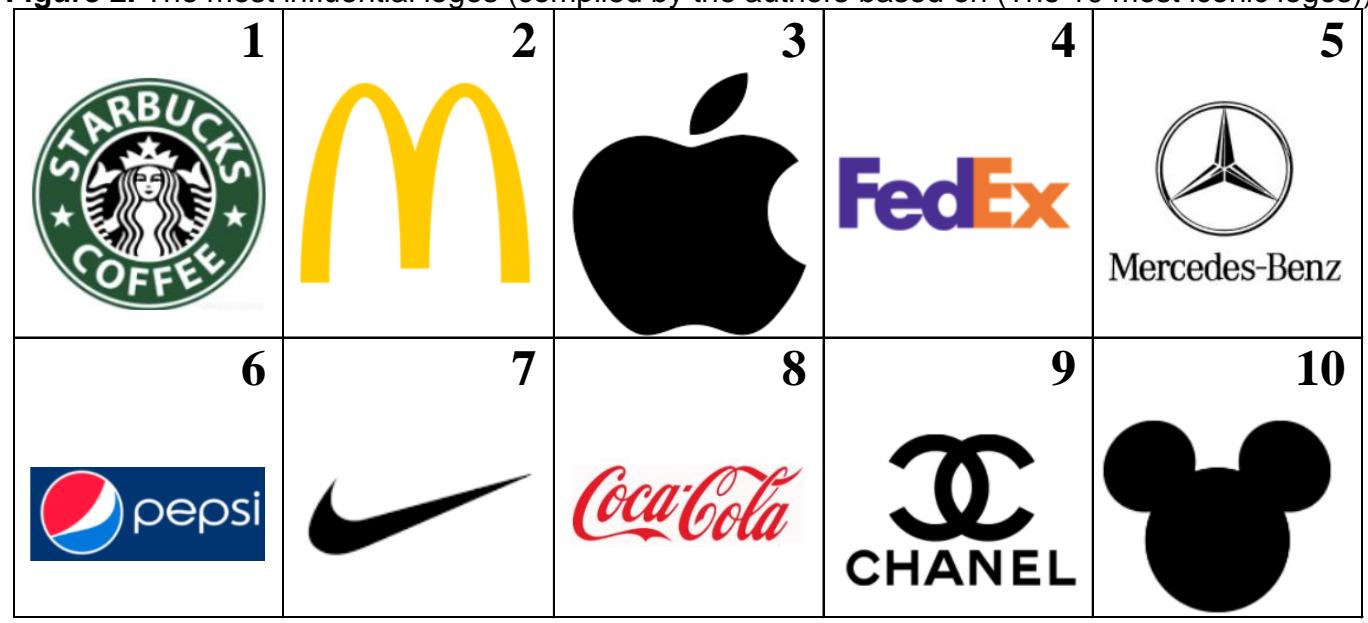

3. Packing. The packaging is a container, the material in which the product is placed. It is intended for preservation of properties of the goods after its manufacturing, giving of a cargo of compactness for convenience of transportation. Well-designed branded packaging is a guarantee that the end consumer will use the "sundress radio" and thus further promote the brand. Fierce competition and demanding buyers are increasingly forcing unconventional decisions. Differentiation is one of the most successful strategies to rise above the competition. Last but not least, it is valid for packaging. This can apply to specific solutions in detail, as well as to the entire design. Therefore, with all the variety of the standard program of packaging manufacturers, you can develop entirely new exclusive solutions for packaging. Creative design and many years of experience in the latest technology go hand in hand. It should be borne in mind that quality packaging will be used several times, even after the end of the product, and this is additional advertising for the manufacturer.

4. Label. A label is a label on a product, product, etc. indicating the name, manufacturer, date of manufacture (or expiration date) and other information about him. The key to the success of a good label is the joint work of professional designers and consumers of products. The label can be either one-sided or with a counter-label. The advantage of the latter over the cheapness of the former is that it looks better, because the front part is not "contaminated" with additional text material, and on the counter-label, you can write in more detail about the product, its properties, conditions of use and storage.

The label contains the following information:

- product description;

- the technology of surface preparation before material application;

- the technology of use;

- pictures that demonstrate this;

- expiration date;

- information about the manufacturer;

- website of the company or trademark;

- particular qualities of the product that should be paid attention to, such as: environmentally friendly, does not contain asbestos, does not contain preservatives, etc.

At this stage, you need to refer to Ukrainian law and find out what information should be on the label to avoid fines and penalties in the future. If the company plans to sell products abroad, it will be advisable to post information in other languages. The story must be read very carefully before the issue because the circulations are usually large, and the error can be very costly. The cost label occupies a significant place in the cost of production. We should not forget that the label is, first of all, an image, it is the visual attraction of the client. That is, if the product is of poor quality, no bright 
and beautiful memorable label will increase its sales and vice versa - with satisfactory product quality and optimal price/quality ratio, buyers will be less interested in what is pasted on the jar. The main thing when optimizing is not to lose common sense and not to save on everything, the manager should always remember the essential functions of the label.

5. Slogan. Slogan - a short easily remembered phrase, especially one used to advertise an idea or a product (Cambridge Dictionary); it is a short sentence or phrase that contains necessary advertising information (Häkkinen, 2016). At the heart of any slogan are two parameters - its marketing and artistic value. The development of a slogan that is easy to remember, beautiful, bright and resonant, provides the company with recognition. The most famous brands usually have one slogan, and sometimes several. Slogans, which are very often repeated in the media, influence consumer decision-making, causing them to respond emotionally. A good slogan does not have to be correct in terms of literary language. Incorrect spelling or pronunciation helps to attract attention, can make it more effective. Its effectiveness depends on such factors as memorable and informative, because it carries the emotional load of the entire advertising campaign, largely shapes the image of the product and the consumer's attitude to it.

Slogans are classified into product and corporate. Commodity - those that are designed to promote goods or services on the market, corporate - are intended to create a positive image of the company itself.

Corporate (image) slogan is developed for greater identification of the company, brand in the market. This is achieved by emphasizing the main feature of the company's activities, which applies to all products or services. The image creates the necessary emotional atmosphere around the company, focuses the attention of the target audience on the intangible features of the brand.

The task of sales (product, brand) slogan - to convey to the consumer the advantage of the product over the product of competitors, to create an emotional attitude of the consumer to the product, to encourage purchase. Sales (product) slogan is the first impression that the consumer has about the brand.

Therefore, this is the kind of slogan that needs to be developed in our case. It must meet the following requirements:

- organic connection with corporate style;

- focus on the characteristics of the target audience;

- should be well remembered;

- be original;

- should exclude ambiguous interpretation.

Trademark positioning

First, the manager should decide what kind of brand will be created: the only brand of the company or individual name. The advantage of single brand names is that in terms of marketing investments, they are more economical, more recognizable and, as a rule, such brands are more comfortable to represent in the market. On the other hand, individual names make it possible to segment the market more clearly, to reduce the potential losses of the supplier in case of failure of one of its brands. The mixed approach and branding of a product group is a desire to balance these two approaches.

The trend of expanding the family of independent brands is a thing of the past: the risk of failure at high marketing costs is too high. Today, companies focus on one or more reputable brands, using them as an "umbrella" or a basis for the production of additional goods and services (brand expansion strategy).

\subsection{Brand management models}

In world practice, there are two main models of product management: 
- Anglo-American or Western;

- Japanese or Oriental.

Western management model. According to this model, companies that produce different products or several product lines, position each of their products uniquely, without linking it to other products and the company as a whole. Creating a new brand on this model is a long-term investment, so special attention is paid to the production, marketing and advertising of goods. In this case, the brand does not necessarily have to generate income immediately; it can become profitable only after a few years.

In the Western sense, a brand is an independent "combat unit" with a well-established target audience and a positive image. Also, an advertising campaign from year to year can be based on one brand idea. Thus, over the years, consumer loyalty to the brand is formed, recognizability and the level of trust in the company increases.

Eastern management model. This management model allows companies to focus on investing in research and development and maintaining consistently high product quality. Besides, there are no "free" stand-alone products, and there is a system of "subbrands" - umbrella brands. Manufacturers focus all their efforts on promoting the company itself, maintaining its image and reputation - as a guarantor of high quality. In this case, a unique role is played by corporate identity, and brand attributes, which are used in all types of communication with the consumer and are mandatory elements of every advertising campaign.

Brand management in Ukraine tends more towards the Western Anglo-American model, with rare features of the Japanese model. As a rule, brand management is carried out by marketers or brand managers. Still, in the absence of such specialists in the company's staff, companies resort to the services of branding agencies.

\section{Results: Creating and evaluating a brand strategy}

Creating a brand strategy is a significant step in building a brand. But in most cases, Ukrainian companies start working on a brand strategy 3-5 years after entering the market, because the emphasis is first on the product and distribution. However, more and more organizations are starting to think from the beginning about who their consumer is, why he should be fascinated by the new brand, and how to beat competitors. And another positive shift: in recent years, owners are more consciously going to build a brand. This means that there will be more strong brands.

We offer such an algorithm for creating a brand strategy (Fig. 3).

Step 1. Awareness of the aspirations and ambitions of the owner. The minimum term for building a brand is three years. During this time, the idea is engraved in people's minds and then is reflected in sales growth. Creating a brand strategy should start with finding out if the owner or manager of the company needs a brand at all.

Step 2. Analysis of the market and competitors. The brand strategy depends on the level of market development and how structured it is. If the business is operating in a young market, the strategy should be more aggressive. If the market has reached the stage of maturity, it is necessary to move in the direction of niche products.

Step 3. Audit of the brand/brand portfolio. This is a crucial step that a company must go through to create a brand or to identify ways to develop it further. Here management needs to analyze the questions (see Fig. 3). The task of this stage is to explore what the main problems may arise. They may relate to the perception of the brand, the level of distribution, the attitude of sellers, the lack of a common understanding of the values of the brand within the company, the price is unclear to the buyer, and so on.

Step 4. Rethinking the target market, developing or adjusting brand positioning. The essence of this process can be expressed in the words of one owner: Why would a person who is now buying 
something else, in the new conditions buy my brand? Will the target group you want to work with disappearing in three to five years?

Step 5. Optimization of brand architecture and the creation of a new concept of assortment. Very often, customers ask: "I want to bring to market something new - to do it under the same brand or another?". Three factors determine the decision about the architecture (leave it unchanged, create a subbrand or a new brand): the target group, the value of the product, and the price. As the experience of many companies shows, a new brand can usually be recommended to create when there are significant differences in the product, target purchase and price (i.e. in all three factors). The need for a new brand may be because the products are very different in terms of consumption situation and motive for purchase. A subbrand is created in cases where one or two factors differ.

Figure 3. Algorithm for creating a brand strategy

\begin{tabular}{|c|c|c|c|c|}
\hline Step 1 & \multicolumn{4}{|c|}{ Awareness of the aspirations and ambitions of the owner } \\
\hline Step 2 & \multicolumn{4}{|c|}{ Analysis of the market and competitors } \\
\hline Step 3 & \multicolumn{4}{|c|}{ Audit of the brand/brand portfolio } \\
\hline & \multicolumn{2}{|c|}{ Does the brand name correspond to its essence? } & \multicolumn{2}{|c|}{ What is special about the brand? } \\
\hline & What does the buyer believe in? & \multicolumn{3}{|c|}{ How precisely is the product focus of the brand defined? } \\
\hline & \multicolumn{2}{|c|}{ How does your brand hold the consumer? } & \multicolumn{2}{|c|}{ Iow recognizable is the brand for the buyer? } \\
\hline & \multicolumn{4}{|c|}{ How attractive is the brand style and packaging of the brand for the buyer? } \\
\hline & \multicolumn{2}{|c|}{ How do consumers perceive product quality? } & \multicolumn{2}{|c|}{ How well defined is the target group? } \\
\hline & \multicolumn{2}{|c|}{ What prevents the brand from growing? } & \multicolumn{2}{|c|}{ What should be the brand architecture? } \\
\hline & \multicolumn{2}{|l|}{ How many subbrands is it needed? } & \multicolumn{2}{|c|}{ What tasks do they have to solve? } \\
\hline \multirow[t]{3}{*}{ Step 4} & \multicolumn{4}{|c|}{ Rethinking the target market, developing or adjusting brand positioning } \\
\hline & \multicolumn{4}{|c|}{ Why would a person who is now buying something else, in the new conditions will buy my brand? } \\
\hline & \multicolumn{4}{|c|}{ Will the target group you want to work with disappear in three to five years? } \\
\hline \multirow[t]{2}{*}{ Step 5} & \multicolumn{4}{|c|}{ Optimization of brand architecture and creation of a new concept of assortment } \\
\hline & target group & \multicolumn{2}{|c|}{ the value of the product } & price \\
\hline Step 6 & \multicolumn{4}{|c|}{ Development of communication messages and promotion strategies } \\
\hline
\end{tabular}

\begin{tabular}{|} 
The main questions to be answered by the brand strategy \\
\hline How many brands does the company need to achieve business goals? What is each brand needed for? \\
Who or what is the source of business? What needs to happen to start buying your brand and not another? \\
What are the values of the brand that differentiate it from others? Is there an inspiring idea? What is the \\
positioning of the brand on a rational and emotional level, brand architecture, range? \\
What should be the directions of bringing new products to the market?
\end{tabular}

Step 6. Development of communication messages and promotion strategies. At this stage, it is determined - what and in what sequence should be communicated to the target group. A right message is specific, understandable and able to arouse interest in the brand. As a rule, a brand strategy is created in two or three stages. For each, the main channels of communication, strategic imperatives, tools that help to form a lasting relationship with the brand are identified. If at the launch stage it is not a question of trust, you shout more about yourself, then at the transition to the growth stage - a critical task is to form a relationship of trust between the brand and the buyer. If the brand needs to rejuvenate the target group - then the brand strategy prescribes specific steps how to achieve this. In general, the main challenge facing every brand manager is not to let the 
brand age. Signs of brand ageing (sales are more complicated, inventories are increasing) should alert the brand manager. This means that the brand is not relevant enough for its target group. In this situation, you need to conduct a brand audit.

Formation of a strategy for the development and management of an enterprise brand is a long process. Marketing professionals estimate the time it takes to build a brand as 3 to 7 years. Throughout the entire period of development and brand management, it is necessary to continually take into account the interests of consumers, the relevance of the needs of the brand, fashion, etc. At the same time, the entire cycle of forming a strategy for developing and managing a brand is based, first of all, on close interaction with the consumer. In Fig. 4 shows a comprehensive scheme for the formation of a strategy for the development and management of an enterprise brand. The scheme represents a system that allows you to combine the interests, goals and motives of the participants in the strategy to improve the efficiency of their relationship and get the company that owns the brand, super-profits concerning competitors.

The adequacy of the implementation of the proposed scheme for the formation of a strategy for the development and management of a brand of an enterprise is based on the fulfilment of specific requirements for an enterprise developing a brand, in particular, for the efficiency of the branding unit in its structure, forms and methods for assessing the rationality of management decisions, as well as for the whole organizational and economic model of the enterprise in the market.

The development and management of a brand, or the branding process in an enterprise should be strategic and holistic; that is, it should be confirmed by an appropriate system of assessment indicators. Enterprise brand development and management must focus on creating a brand image, for which all marketing efforts must be combined. In a long-term project, a well-formed brand image should generate a rise in brand strength, which in turn will provide reliable and sustainable added value for products in the future.

Figure 4. A comprehensive scheme for the formation of a strategy for the development and management of an enterprise brand

Company
in the brand building
process

In different ways of constructing a system of indicators characterizing the process of developing and managing an enterprise brand, the assessment is expressed in terms of various dimensions. In some, the process of developing and managing a brand can be quantified according to the monetary value of brand value. In this case, measures for the development and management of a brand can be presented as a result of achieving an actual monetary amount equal to future income. In others, focused on quality indicators, the process of developing and managing a brand is determined by the additional benefits of the products/services of a given brand, which best fits the meaningful concept of brand value and Brand Equity. 
When evaluating a brand, a financial model of building a system of indicators (BEES - Brand equity evaluation system ranking) is often used, which is a multi-factor system of brand evaluation indicators that takes into account the characteristics of the industry in which the company operates. Fig. 5 schematically reflects the possibilities of constructing a system of indicators characterizing the process of developing and managing an enterprise brand based on this model. The main advantage of using the BEES model is that it is adaptable to the enterprise industry.

A variety of methods for constructing a system of indicators for the development and management of an enterprise's brand allows us to assert that when using different ways of measuring a brand, differentiated values are obtained. Therefore, it is necessary to take into account several requirements for assessing the process of developing and managing an enterprise brand:

- balance between financial performance and quality assessment of consumers;

Figure 5. Building a system of indicators characterizing the process of developing and managing a brand based

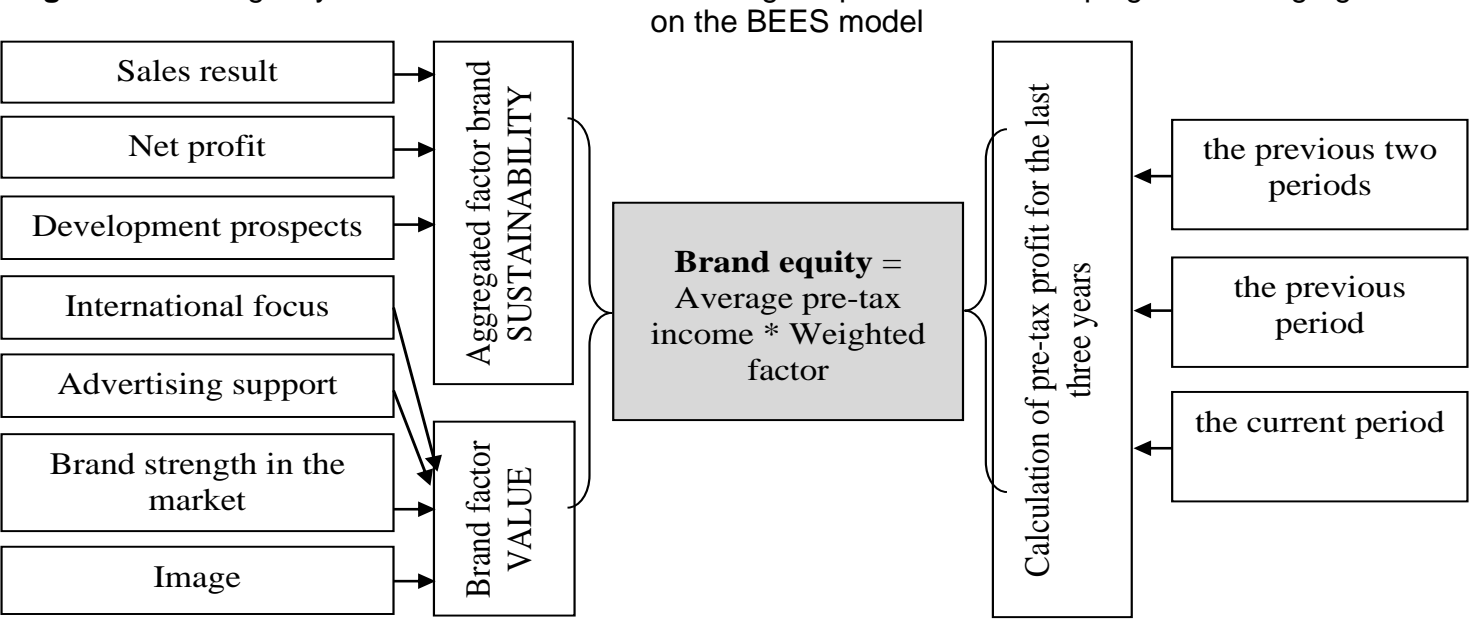

- balance between objective indicators (sales volume, market share, price, distribution) and subjective (brand awareness, perceived quality, brand attractiveness, intention to buy products of this brand, loyalty);

- the approach chosen to assess the development and management of an enterprise's brand at its cost should be used as a means of brand management and should include determining the status of the brand;

- the brand asset must be measured in monetary value;

- the model for building a system of indicators of development and brand management should be easily modified and adapted;

- it is necessary to take into account the intangible asset of the brand, to distinguish between the success of the product and the brand itself;

- the model should be suitable both for evaluating the process of developing and managing the brand of an enterprise and for considering these processes concerning its product.

In a modern economy, it is advisable to conduct both monetary and non-monetary (combined) assessment of the development and management of an enterprise brand.

As mentioned above, it is necessary to monitor and prevent "brand ageing". To track this aspect, we propose to periodically (once every 3-6 months) build a brand "health" chart, which makes it possible to assess its viability (Fig. 6).

So, in the above example, the analyzed brand enjoys strong support from the "organizational brand culture", but has problems in terms of "implementation and search for brand resources" and "brand market share". 
Figure 6. Brand Health Chart

\begin{tabular}{|c|c|c|c|c|c|c|}
\hline \multirow{2}{*}{ Indicators } & \multicolumn{4}{|c|}{ Weak degree } & \multicolumn{2}{|c|}{ Strong degree } \\
\hline & 0 & 1 & 2 & 3 & 4 & 5 \\
\hline Organizational brand culture & & & & & & \\
\hline Brand vision & & & & & & \\
\hline Brand objectives & & & & & & \\
\hline Brand essence & & & & & & \\
\hline Implementation and search fo & & & & & & \\
\hline Brand market share & & & & & & \\
\hline Brand revenue & & & & & & \\
\hline Organizational brand culture & & & & & & \\
\hline
\end{tabular}

\section{Conclusion.}

Today, the number of managers in Ukrainian companies who are aware of the importance of creating and promoting their brand has increased. Of particular importance is the management of the brand (product). Brand management allows you to take a strong position in the market in conditions of fierce competition, gain the trust and loyalty of consumers, strengthen the company's reputation and brand image. The brand itself is not the key to the successful operation of the company.

Simply creating a brand is not enough, you need to conduct marketing and advertising activities continually, assess the value and design of the brand, plan brand promotion and development strategy - all these are components of the process of brand management or brand management.

The primary purpose of the brand development strategy is to achieve competitive advantages and ensure the competitiveness of the enterprise. Therefore, in modern enterprises that seek to succeed in competition, appropriate organizational and economic mechanisms for managing brand development should be developed and implemented. The results of the study, which are covered in this article, deepen the theoretical and methodological foundations of brand management in terms of formation and implementation of brand development strategy to increase the competitiveness of the enterprise.

\section{References}

1. A Dictionary of Business and Management (2016). Oxford University Press; 6th Edition, $624 \mathrm{p}$.

2. Aaker, D. (1996). Building Strong Brands, Free Press, Business \& Economics, $380 \mathrm{p}$.

3. Buil, I., Catalán, S., \& Martínez, E. (2016). The importance of corporate brand identity in business management: An application to the UK banking sector, BRQ Business Research Quarterly, Volume 19, Issue 1, pp. 3-12

4. Cambridge Dictionary. Slogan. https://dictionary.cambridge.org/dictionary/english/slogan

5. Dźwigoł, H., Shcherbak, S., Semikina, M., Vinichenko, O., \& Vasiuta, V. (2019). Formation of Strategic Change Management System at an Enterprise. Academy of Strategic Management Journal, 18(SI1), 1-8. Retrieved from https://www.abacademies.org/articles/Formation-ofstrategic-change-management-system-at-enterprise-1939-6104-18-SI-1-454.pdf

6. Häkkinen, M.-M. (2016). "Be Our Guest" - A Linguistic Study of Destination Slogans, https://trepo.tuni.fi/bitstream/handle/10024/100085/GRADU1479373517. pdf?sequence $=1$ \&isAllowed $=y$

7. Heding, T., Knudtzen, C., \& Bjerre M. (2020). Other categorizations of brand management, May In book: Brand Management, DOI: 10.4324/9780367172596-15

8. Johansen, T. (2018). Branding/Brand Management, DOI: 10.1002/9781119010722.iesc0013 
9. Kapferer, J.-N. (2012). The new strategic brand management: Advanced insights and strategic thinking (5th ed.). London, UK: Kogan Page, 512 p.

10.Makasi, A., Govender, K., \& Madzorera, N. (2014). Rebranding and Its Effects on Consumer Perceptions: A Case Study of a Zimbabwean Bank, Mediterranean Journal of Social Sciences 5(20), pp. 2582-2588. DOI: 10.5901/mjss.2014.v5n20p2582

11.Mazaraki, A., Boiko, M., Bosovska, M., \& Kulyk, M. Multi-agent information service system of managing integration processes of enterprises, Naukovyi Visnyk Natsionalnoho Hirnychoho Universytetu, 2020, 2020(3), pp. 103-108

12.Stošić-Mihajlović, L., \& Trajković, S. (2020). Branding and brand management in international business, Journal of Process Management New Technologies, 8(2), pp. 38-44 DOI: 10.5937/jouproman8-26139

13.The 10 most iconic logos of all-time. https://www.readyartwork.com/10-most-iconic-logos-alltime/

14.Vienne, V. (1999). The Brand Named Walter Landor, Graphis, No. 321, pp. 102-107. 